\title{
Studi Eksperimental Kedalaman Aus dan Koefisien Gesek Akibat Stick-Slip pada Reciprocating Wear
}

\author{
Rahmat Raja Barita Siregar dan Yusuf Kaelani \\ Departemen Teknik Mesin, Fakultas Teknologi Industri, Institut Teknologi Sepuluh Nopember (ITS) \\ e-mail: y_kaelani@me.its.ac.id
}

\begin{abstract}
Abstrak-Dalam dunia industri sering ditemukan suku cadang yang mengalami gaya gesek statis dan kinetis. Perubahan gaya gesek dari statis ke kinetis disebut stick-slip friction. Pada daerah terjadinya stick-slip friction, dampak gaya gesek yang terjadi mempunyai nilai yang paling besar, sehingga fenomena stick-slip friction ini cukup berpengaruh terhadap umur pakai dari suatu material. tujuan dari penelitian ini adalah untuk mengkaji hubungan variasi pembebanan terhadap keausan material dan nilai koefisien gesek saat terjadi fenomena stick-slip friction dengan menggunakan material pin baja ST-41 yang secara umum lebih mudah ditemukan di pasaran agar dapat bermanfaat secara lebih luas. Metode yang dilakukan adalah pengujian eksperimantal menggunakan tribometer tipe pin-on plate. Dari hasil penelitian ini didapatkan semakin besar pembebanan maka semakin besar keausan yang ditimbulkan oleh gesekan stick-slip. Selisih kedalaman titik gesekan stick-slip dan titik gesekan sliding pada pembebanan $20 \mathrm{~N}$ sebesar 39,5 $\mu \mathrm{m}$ lebih kecil daripada pembebanan $30 \mathrm{~N}$ sebesar $40,5 \mu \mathrm{m}, 30 \mathrm{~N}$ lebih kecil daripada $40 \mathrm{~N}$ sebesar $73 \mu \mathrm{m}$. Sehingga dapat ditarik kesimpulan bahwa semakin besar pembebanan maka semakin besar keausan yang ditimbulkan oleh gesekan stick-slip. Nilai koefisien gesek pada area stick-slip dengan pembebanan $20 \mathrm{~N}$ sebesar 3.064677686, $30 \mathrm{~N}$ sebesar 2.624380797 dan $40 \mathrm{~N}$ sebesar 1.552499331 cenderung menurun seiring dengan meningkatnya besar pembebanan.
\end{abstract}

Kata Kunci- koefisien gesek, Pengujian tribometer, stick-slip friction, sliding friction.

\section{PENDAHULUAN}

$\mathrm{T}$ RIBOLOGY adalah salah satu ilmu terapan di bidang Teknik mesin yang mempelajari gesekan, keausan dan pelumasan, memberikan kontribusi dalam upaya meminimalkan keausan akibat kontak antara dua permukaan, sehingga dapat diterapkan di industri untuk menganalisa kasus kegagalan atau kerusakan pada komponen mesin

Salah satu fenomena yang terjadi dalam bidang pemesinan adalah fenomena kontak antar komponen. Kontak yang terjadi antar komponen bisa berupa static contact, rolling contact, atau sliding contact. Kontak mekanik (contact mechanics) merupakan hal yang penting, karena dapat mempelajari bagaimana struktur topografi permukaan (asperity) mengalami deformasi.

Gaya yang ditimbulkan oleh dua benda yang bergesekan dan arahnya berlawanan disebut dengan gaya gesek. Gaya gesek atau friction yang terjadi pada benda padat terdiri dari dua jenis, yaitu gaya gesek statis dan gaya gesek kinetis. Jika benda yang mengalami kontak tidak mengalami pergerakan, maka gesekannya disebut dengan gesekan statis. Jika gaya yang dikerjakan cukup untuk menggerakkan benda, maka gerakannya disebut dengan gaya kinetis [1]. Namun, gesekan dapat saja mempunyai gabungan antara statis dan kinetis sehingga dampak yang terjadi pada keausan menjadi sangat besar [2]. Gesekan tersebut adalah stick-slip friction. Stick-slip friction juga terjadi ketika gerakan suatu benda mencapai kecepatan nol atau diam seketika kemudian bergerak kembali. Fenomena tersebut dapat kita jumpai pada ring piston dengan silinder ruang bakar, pintu geser dengan permukaan tanah, rel tinta printer, dan rel mesin cnc. Oleh karena itu penulis melakukan riset ini agar hasilnya dapat diterapkan sebagai acuan ketika mendisain komponen yang mengalami gesekan stick-slip

Penelitian kali ini dilakukan untuk mengetahui koefisien gesek dan fenomena stick-slip dari sebuah kontak material yang akan digunakan pada tribometer reciprocating pin on plate. Pengujian dilakukan dengan cara menjalankan alat tribometer sejauh $1440 \mathrm{~m}$ dengan beban $20 \mathrm{~N}, 30 \mathrm{~N}, 40 \mathrm{~N}$ yang direkam dengan kamera, lalu memplot profil lintasan aus dengan bantuan dial indicator dengan cara menggambil kedalaman aus sepanjang lintasan dengan jarak tiap titik pengukuran sebesar $1 \mathrm{~mm}$, kemudian membandingkan keausan daerah stick-slip dengan sliding menggunakan rasio kedalaman, kemudian menganalisa efeknya. Kemudian mencari nilai koefisien gesek dengan mengekstrak video rekaman alat tribometer. Melalui penelitian ini kita dapat mengetahui nilai koefisien gesek dan fenomena yang terjadi pada daerah stick-slip.

Pada penelitian sebelumnya yang dilakukan oleh Ruben [3] digunakan material uji steel ST-37 dengan acrylic, namun pada penelitian ini menggunakan materian steel ST-41 karena material ini mudah didapat, banyak digunakan di dunia industri, rumah tangga dan alat kesehatan sehingga dirahapkan openelitian ini dapat berguna dengan lebih luas.

\section{METODE PENELITIAN}

Penelitian ini dilakukan melalui beberapa langkah kerja sebagai studi eksperimental. Awalnya melakukan persiapan spesimen, yaitu membuat pin yang terbuat dari baja ST-41 berbentuk setengah bola dan spesimen plate akrilik. Penelitian dilakukan dengan menggunakan alat uji tribometer tipe Pin on Plate. Pin diletakkan diatas plate yang bergerak secara reciprocating dengan menggunakan cylinder pneumatic. Pada penelitian ini digunakan kecepatan sliding sebesar $0,1 \mathrm{~m} / \mathrm{s}$ dan jarak lintasan sliding sejauh $1440 \mathrm{~m}$ Variasi yang diberikan 
berupa pembebanan sebesar $20 \mathrm{~N}, 30 \mathrm{~N}, 40 \mathrm{~N}$. Kondisi yang diberikan yaitu kontak dua material yang tidak diberi pelumasan atau dry sliding. Keausan dilihat dari perubahan kedalaman plate yang terjadi pada lintasan gesek antara pin dengan plate. Perubahan kedalaman plate didapatkan dengan menggunakan dial indicator yang ujung jarumnya telah dimodifikasi menjadi lebih kecil. Pada saat pengujian direkam menggunakan kamera video yang kemudian di ekstrak menggunakan software kinovea untuk mendapatkan data perubahan waktu dan tekanan pneumatic pada setiap titik dengan jarak tiap titik sebesar $1 \mathrm{~mm}$. Berikutnya mulai menghitung nilai koefisien gesek pada setiap titik dengan menggunakan rumus seperti persamaan dibawah ini:

$$
\sum \mathrm{F}=\mathrm{m} . \mathrm{a}
$$

Keterangan (satuan) : $\sum \mathrm{F}=$ resultan gaya $\left(\mathrm{Kg} \mathrm{m} / \mathrm{s}^{2}\right)$

$$
\mathrm{m}=\text { Massa Benda }(\mathrm{Kg})
$$$$
\mathrm{a}=\operatorname{percepatan}\left(\mathrm{m} / \mathrm{s}^{2}\right)
$$

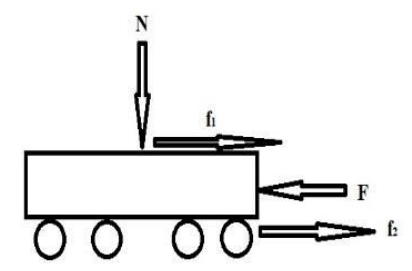

Gambar 1. Free Body Diagram suatu benda.

$$
\begin{aligned}
& \sum \mathrm{F}=\mathrm{m} \cdot \mathrm{a} \\
& \mathrm{F}-\mathrm{f}_{1}-\mathrm{f}_{2}=\mathrm{m} \cdot \mathrm{a} \\
& \mu=(\mathrm{F}-(\mathrm{m} \cdot \mathrm{a})) / \mathrm{N} \\
& \operatorname{dimana}: \mathrm{F}=\mu \cdot \mathrm{N} \\
& \mathrm{f}_{2} \text { diasumsikan } 0
\end{aligned}
$$

\section{HASIL DAN DISKUSI}

\section{A. Analisa koefisien gesek}

Hasil perhitungan data kecepatan, percepatan, dan koefisien gesek yang sudah dilakukan kemudian akan dianalisa ke dalam bentuk grafik untuk dapat dilihat perbandingan antara tiap pembebanan dan yang berbeda-beda. Dari grafik tersebut dapat dilakukan analisa perbandingan antara teori dengan hasil eksperimen. Grafik fungsi $\mu$ terhadap jarak pada pembebanan 20N, 30N, 40N dengan grafik di tunjukan pada Gambar 2.

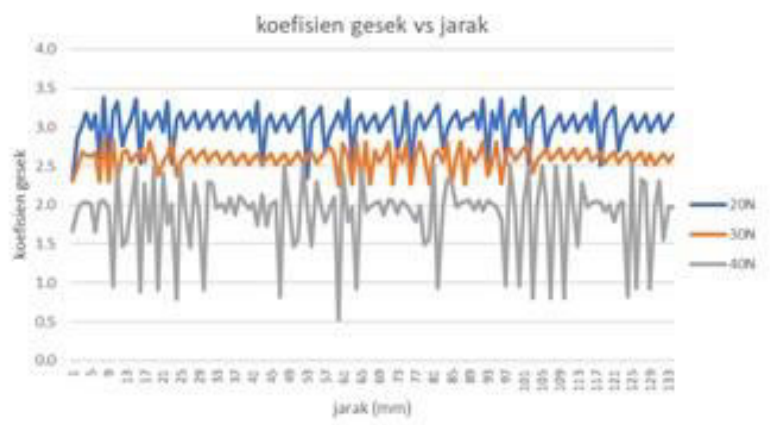

Gambar 2. hubungan koefisien gesek vs jarak.

Grafik pada gambar 2 merupakan grafik yang menbandingkan besar koefisien gesek pada setiap titik dengan pembebanan $20 \mathrm{~N}, 30 \mathrm{~N}, 40 \mathrm{~N}$. pada trendline warna biru menunjukan hubungan antara besar koefisien gesek dengan posisi untuk pembebanan $20 \mathrm{~N}$, kemudian trendline berwarna oranye menunjukan hubungan antara besar koefisien gesek dengan posisi untuk pembebanan $30 \mathrm{~N}$, lalu trendline warna abu-abu menunjukan hubungan antara besar koefisien gesek dengan posisi untuk pembebanan $40 \mathrm{~N}$. Pada grafik tersebut ditampilkan besarnya koefisien gesek sebagai sumbu vertikal dan besar perubahan posisi dengan satuan $\mathrm{mm}$ sebagai sumbu horizontal. Pada grafik tersebut, dibandingkan harga koefisien gesek dari 133 titik yang berbeda.

Pada grafik koefisien gesek dengan pembebanan 20N terlihat bahwa koefisien gesek pada titik 0 sebesar 2.32566 mengalami kenaikan secara tajam hingga titik 4 sebesar 3,17884 kemudian pada titik 6 hingga titik 24 nilai koefisien gesek naik dan turun secara tidak beraturan lalu naik dan turun secara konstan hingga titik 41. Pada titik 42 hingga titik 107 kembali mengalami kenaikan dan penurunan nilai koefisien gesek secara tidak teratur lalu sempat teratur kembali hingga titik 116 sebelum kembali menjadi tidak teratur hingga titik 123, dan pergerakan kenaikan dan penurunan koefisien gesek kembali terjadi hingga titik 133.

Pada grafik koefisien gesek dengan pembebanan 30N terlihat bahwa pada titik 0 hingga titik 25 nilai koefisien gesek naik dan turun secara tidak beraturan kemudian perubahan nilai koefisien gesek cenderung teratur hingga titik 52. Pada titik 56 hingga 105 nilai koefisien gesek kembali naik dan turun secara tidak beraturan, setelah itu cenderung teratur hingga titik 133

Pada grafik koefisien gesek dengan pembebanan 40N terlihat bahwa dari titik 0 hingga titik 10 nilain koefisien gesek naik dan turun secara perlahan kemudian grafik mulai naik dan turun secara drastis hingga titik 33 dan kembali berubah secara perlahan hingga titik 45 . Pada titik 46 hingga 66 grafik kembali mengalami kenaikan dan penurunan yang drastic kemudian cenderung turun secara perlahan hingga titik 79 . Pada titik 80 sampai 87 grafik sempat naik dan turun secara tajam sebelum kembali turun secara perlahan hingga titik 96. Antara titik 96 dan 115 nilai koefisien gesek naik dan turun secara tajam sebelum kembali perlahan menurun hingga titik 123, kemudian naik dan turun secara tajam kembali hingga titik 133.

\section{B. Analisa kedalaman aus}

Pengujian kedalaman aus dilakukan dengan cara menggesekan Steel ST41 dengan Acrylic secara bolak balik dan tanpa pelumasan kemudian lintasan gesek diukur dengan menggunakan dial indicator. Hasil dari pengujian kedalaman aus pada Steel ST41 dan acrylic tanpa menggunakan pelumas (Dry Sliding) disajikan dalam bentuk diagram kedalaman vs posisi seperti dapat dilihat pada Gambar 3 - 5 berikut ini: 


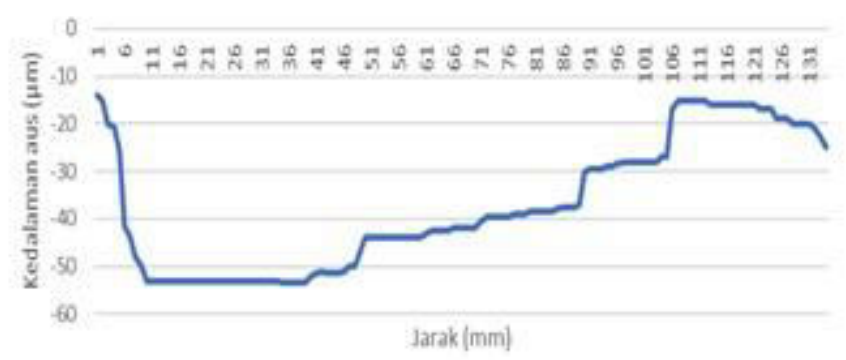

Gambar 3. hubungan kedalaman vs posisi pada pembebanan 20 N.

Pada gambar 3 kedalaman aus yang terjadi pada akibat pengujian dengan pembebanan $20 \mathrm{~N}$ cenderung fluktuatif. Pada titik 0-12 kedalaman aus cenderung menurun drastis dari $-14 \mu \mathrm{m}$ hingga $-19 \mu \mathrm{m}$ kemudian kedalaman aus cenderung stabil hingga titik 39 dan kedalaman aus kembali naik perlahan pada titik 39 - 47. Pada titik 47-59 terjadi kenaikan kedalaman yang cukup drastis dari $-50 \mu \mathrm{m}$ hingga $-44 \mu \mathrm{m}$ kemudian terus naik secara perlahan hingga titik 89 dengan kedalaman aus sebesar $-30 \mu \mathrm{m}$ lalu kembali naik dengan tajam hingga kedalaman $-29,5 \mu \mathrm{m}$ pada titik 90 . Grafik naik secara perlahan pada titik 90 - 105 dengan kedalaman aus sebesar $29,5 \mu \mathrm{m}$ hingga $-17 \mu \mathrm{m}$, kemudian grafik kembali turun secara perlahan hingga titik 133 sebesar $-25 \mu \mathrm{m}$.

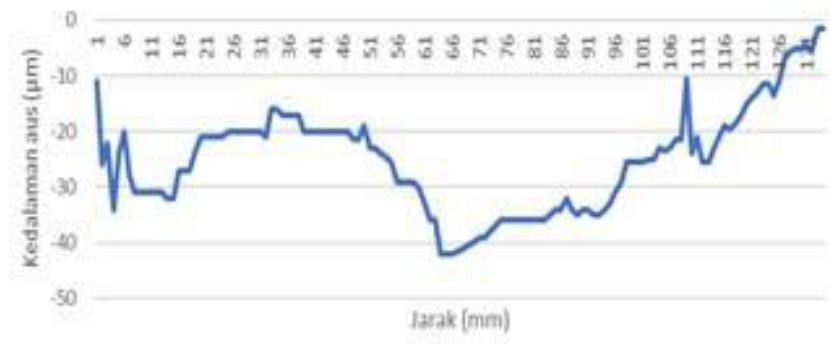

Gambar 4. hubungan kedalaman vs posisi pada pembebanan $30 \mathrm{~N}$.

Pada Gambar 4 diatas terlihat kedalaman aus yang terjadi pada akibat pengujian dengan pembebanan $30 \mathrm{~N}$ cenderung fluktuatif. Pada titik 0 sebesar - $14 \mu \mathrm{m}$ sampai 4 sebesar $-34 \mu \mathrm{m}$ kedalaman aus menurun dengan tajam, diikuti dengan kenaikan yang tajam pada titik 4 sampai 6 sebesar $-20 \mu \mathrm{m}$. Pada titik 6-9 kedalaman turun dengan tajam hingga $-31 \mu \mathrm{m}$ kemudian naik secara perlahan hingga titik 34 sebesar $-16 \mu \mathrm{m}$. pada titik 34-65 kedalaman menurun secara perlahan hingga $-42 \mu \mathrm{m}$. titik 70-108 terjadi kenaikan secara perlahan hingga $-21,5 \mu \mathrm{m}$ diikutin dengan kenaikan drastic hingga titik 109 sebesar $-10,5 \mu \mathrm{m}$, dilanjutkan dengan penurunan secara drastis hingga titik 113 sebesar $-25,5 \mu \mathrm{m}$. pada titik 113-133 grafik mengalami kenaikan secara perlahan hingga kedalaman $-1,5 \mu \mathrm{m}$

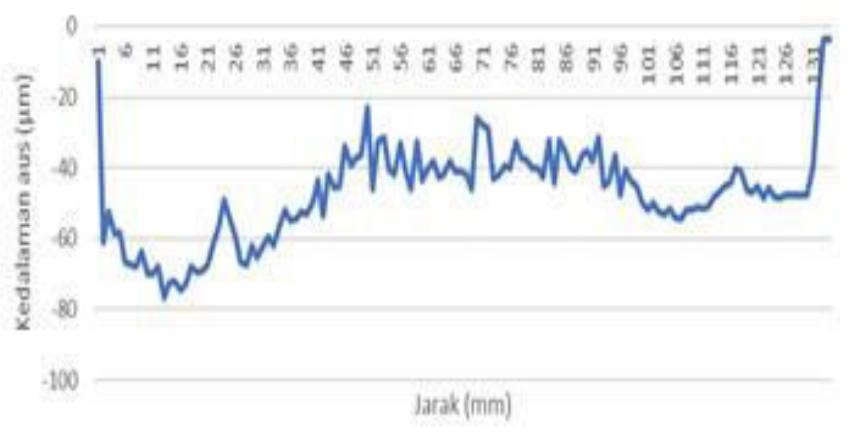

Gambar 5. hubungan kedalaman vs posisi pada pembebanan $40 \mathrm{~N}$.

Pada gambar 5. diatas terlihat kedalaman aus yang terjadi pada akibat pengujian dengan pembebanan $40 \mathrm{~N}$ cenderung fluktuatif. Pada titik 0 sebesar $-10 \mu \mathrm{m}$ mengalami penurunan secara drastis hingga titik 2 sebesar $-61 \mu \mathrm{m}$ kemudian turun secara perlahan hingga titik 13 sebesar $-76,5 \mu \mathrm{m}$ kemudian naik kembali secara perlahan hingga titik 24 sebesar $-49 \mu \mathrm{m}$ lalu turun secara tajam hingga titik 28 sebesar $-67,5 \mu \mathrm{m}$. pada titik 28 - 50 terjadi kenaikan grafik secara perlahan hingga kedalaman $-23 \mu \mathrm{m}$ lalu turun kembali secara perlahan hingga titik 69 sebesar $-46 \mu \mathrm{m}$, kemudian terjadi kenaikan secara tajam hingga titik 71 sebesar $-28 \mu \mathrm{m}$. pada titik 71 hingga 107 terjadi penurunan secara perlahan sebesar $-54,5 \mu \mathrm{m}$, kemudian naik secara perlahan hingga titik 118 sebesar $-41 \mu \mathrm{m}$. pada titik 118 hingga 130 terjadi penurunan secara perlahan sebesar $-47,5 \mu \mathrm{m}$, dilanjutkan dengan kenaikan secara drastis hingga titik 133 sebesar $-3,5 \mu \mathrm{m}$.

\section{Analisa efek stick-slip terhadap perubahan pembebanan}

Efek keausan akibat gesekan stick-slip terhadap gesekan sliding didapatkan dari selisih kedalaman titik gesekan stickslip terdalam dengan titik gesekan sliding, seperti dapat dilihat pada tabel 1. dibawah:

Tabel 1.

Tabel efek keausan

\begin{tabular}{llll}
\hline \hline & $20 \mathrm{~N}$ & $30 \mathrm{~N}$ & $40 \mathrm{~N}$ \\
\hline titik gesekan stick-slip $(\mu \mathrm{m})$ & -53.5 & -42 & -76.5 \\
titik gesekan sliding $(\mu \mathrm{m})$ & -14 & -1.5 & -3.5 \\
selisih kedalaman & -39.5 & -40.5 & -73 \\
\hline \hline
\end{tabular}

Pada tabel diatas dapat dilihat bahwa selisih kedalaman titik gesekan stick-slip dan titik gesekan sliding pada pembebanan $20 \mathrm{~N}$ lebih kecil daripada pembebanan $30 \mathrm{~N}, 30 \mathrm{~N}$ lebih kecil daripada $40 \mathrm{~N}$. sehingga dapat ditarik kesimpulan bahwa semakin besar pembebanan maka besar keausan yang ditimbulkan oleh gesekan stick-slip semakin besar.

Nilai koefisien gesek pada daerah stick-slip didapatkan dari rata-rata nilai koefisien gesek pada titik gesekan stick-slip. Pengaruh perubahan beban pada nilai koefisien gesek daerah stick-slip dapat dilihat pada gambar 6. dibawah: 


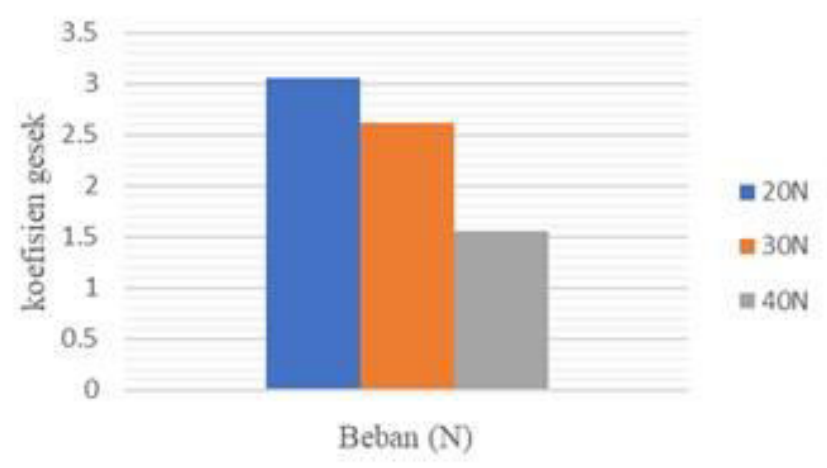

Gambar 6. hubungan koefisien gesek pada daerah stick-slip.

Pada gambar 6 diatas dapat dilihat bahwa nilai koefisien gesek daerah stick-slip pada pembebanan $20 \mathrm{~N}$ lebih besar dari $30 \mathrm{~N}$, dan nilai koefisien gesek daerah stick-slip pada pembebanan $30 \mathrm{~N}$ lebih besar daripada pembebanan $40 \mathrm{~N}$. Sehingga dapat disimpulkan bahwa nilai koefisien gesek pada daerah stick-slip akan semakin berkurang seiring bertambahnya besar pembebanan. Hal ini tidak sesuai dengan penelitian Yoon et al [4] yang menjelaskan bahwa semakin besar pembebanan maka nilai koefisien gesek akan semakin besar, ketidak sesuaian ini mungkin disebabkan oleh perbedaan tipe alat tribometer, sliding speed, besar pembebanan yang diberikan, serta material yang digesekan.

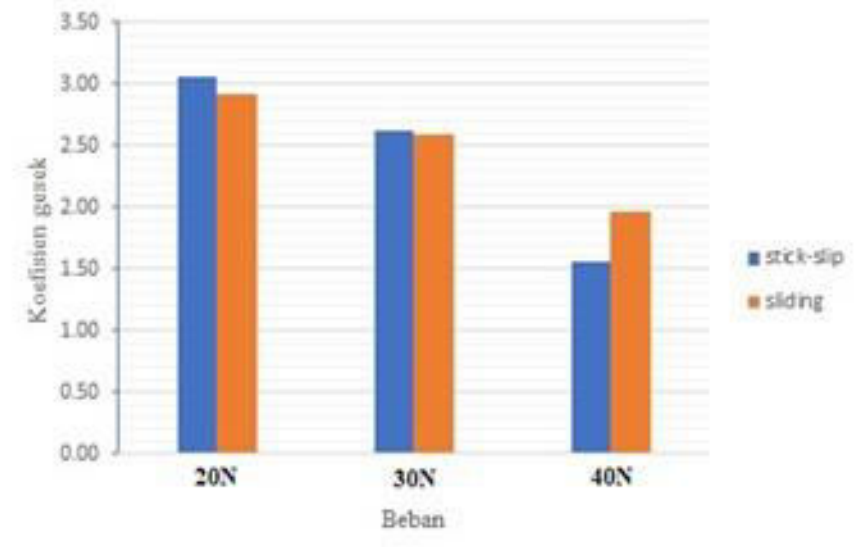

Gambar 7. hubungan koefisien gesek pada daerah stick-slip dengan sliding.

Nilai koefisien gesek pada daerah stick-slip dan sliding didapatkan dari rata-rata nilai koefisien gesek pada titik gesekan stick-slip dan sliding. Pengaruh perubahan beban pada nilai koefisien gesek daerah stick-slip dibandingkan dengan sliding dapat dilihat pada gambar 7 diatas:

Pada gambar 7 diatas dapat dilihat bahwa nilai koefisien gesek daerah stick-slip pada pembebanan $20 \mathrm{~N}$ sebesar 3,06 lebih besar dari daerah sliding sebesar 2,92 dengan selisih koefisien gesek sebesar 0.1418. sedangkan pada pembebanan $30 \mathrm{~N}$ nilai koefisien gesek stick-slip sebesar 2,62 dan sliding sebesar 2,59 dengan selisih koefisien gesek sebesar 0.0317 yang lebih kecil daripada pembebanan 20N. Pada pembebanan $40 \mathrm{~N}$ nilai koefisien gesek daerah stick-slip dengan nilai 1,55 lebih kecil dibandingan dengan koefisien gesek sliding sebesar 1,97 dengan selisih -0.4213 . Sehingga dapat disimpulkan bahwa perbandingan nilai koefisien gesek pada daerah stick-slip dengan sliding akan semakin berkurang seiring bertambahnya besar pembebanan.

\section{KESIMPULAN}

Kesimpulan yang dapat diambil dari penelitian ini adalah sebagai berikut.

1. Selisih kedalaman titik gesekan stick-slip dan titik gesekan sliding pada pembebanan $20 \mathrm{~N}$ sebesar $39,5 \mu \mathrm{m}$ lebih kecil daripada pembebanan $30 \mathrm{~N}$ sebesar $40,5 \mu \mathrm{m}, 30 \mathrm{~N}$ lebih kecil daripada $40 \mathrm{~N}$ sebesar $73 \mu \mathrm{m}$. Sehingga dapat ditarik kesimpulan bahwa semakin besar pembebanan maka semakin besar keausan yang ditimbulkan oleh gesekan stick-slip

2. Nilai koefisien gesek pada area stick-slip dengan pembebanan $20 \mathrm{~N}$ sebesar 3.064677686, $30 \mathrm{~N}$ sebesar 2.624380797 dan $40 \mathrm{~N}$ sebesar 1.552499331 cenderung menurun seiring dengan meningkatnya besar pembebanan

\section{DAFTAR PUSTAKA}

[1] B. Bhushan, Introduction to Tribology. New York: John Wiley \& Sons Inc, 2013.

[2] D. W. Lee, Stick-slip Friction and Wear of Articular Joints. California, 2012.

[3] R. Simatupang, "Studi eksperimen analisa koefisien gesek pada saat terjadi fenomena stick-slip friction pada reciprocating contact," Surabaya, 2016.

[4] S. W. Yoon, M. W. Shin, W. G. Lee, and H. Jang, Effect of Surface Contact Conditions on the Stick-Slip Behavior of Brake Friction Material. Amsterdam: Elsevier Science, 2012. 